\title{
ALCOHOL AND ROAD SAFETY POLICY IN EUROPE:
} SUCCESSES AND FAILURES

doi:10.1136/injuryprev-2012-040580c.28

D Sethi* ${ }^{*}$ F Mitis. World Health Organization Regional Office for Europe

Background In the WHO European Region, road traffic injuries are the leading cause of death in young people aged 5-29years. Alcohol is an important risk factor for severe crashes.

Purpose To discuss of alcohol-related road safety policy in Europe.

Methods Literature review, survey of health ministry focal persons from 49 countries and routine data.

Results The burden of alcohol-related road traffic injury is unevenly distributed. It is more concentrated in the Baltics, Central and Eastern Europe and the Commonwealth of Independent States. The proportion of road traffic deaths attributable to alcohol varies with age and sex, for example, in Western Europe countries in males as $50 \%$ in age $30-44$ and $46 \%$ in age $15-29$ years; in females $25 \%$ and $18 \%$ respectively. The blood alcohol concentration limit ranged from 0 to $0.8 \mathrm{~g} / \mathrm{l}$. Most countries (95\%) reported a national policy for road safety and implemented interventions to prevent alcohol-related road traffic injuries: $39 \%$ of the countries had increased the minimum legal drinking age, $73 \%$ applied sobriety 
checkpoints, $89 \%$ enforced laws on blood alcohol concentration limit but only $22 \%$ had lower limits for novice drivers. As part of their overall policies to control alcohol-related harm, $89 \%$ of countries implemented interventions consisting of fiscal and legal measures and $33 \%$ had health sector based interventions. Enforcement was reported as satisfactory in 31\%.

Significance This paper shows that whereas most countries have policies for alcohol-related road crashes, many need to strive for better implementation. More reliable data and research on sustainable enforcement are needed. 